\title{
AN ALTERNATIVE TREATMENT FOR BIPOLAR AFFECTIVE DISORDER
}

Brás, J. (1); Sousa, R. (1); Costa, L.(1); Melo, B.(1); Teixeira, D.(1); Marques, A.(1); Alves Pereira, C. (1); Pinto Costa, A. (1); Cunha, N.(1)

1 Department of Psychiatry and Mental Health, Centro Hospitalar Tondela-Viseu EPE., Viseu, Portugal

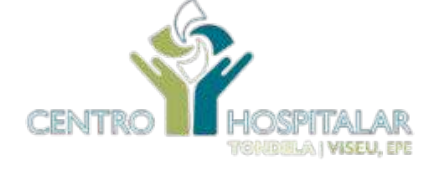

\section{BACKGROUND AND AIMS}

Bipolar affective disorder (BAD) is a psychiatric disease characterized by recurrent episodes of mood disturbance. The patient suffers depressive, manic or hypomanic episodes.

This pathology is treated with mood stabilizers and second-generation antipsychotics. The non-adherence to treatment is a major factor of bad outcomes, and is present in $10-60 \%$ of the cases.

Long-acting injectable second-generation antipsychotics, including paliperidone, are associated with an improvement in treatment adherence and then with better outcomes. Few studies exist in the literature evaluating the effectiveness of paliperidone in BAD, but those existent demonstrated positive results.

Our goal is to present a scientific poster containing a clinical case of bipolar affective disorder treated with paliperidone.

\section{MATERIALS AND METHODS}

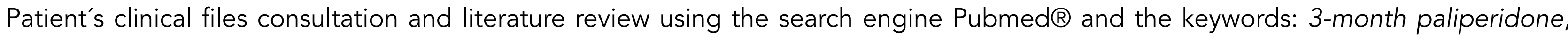
bipolar disease e Trevicta.

\section{RESULTS}

Male, 37 years old

Diagnosis of Bipolar Affective Disorder since 2007

2016

Manic episode with psychotic features:

- Grandiose and religious delusions

- Euphoria and ecstasy

- Lack of insight

"I am Siddártha... me and God are one... I don't need to eat, I don't need to sleep."(sic)

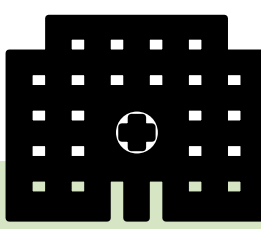

Involuntary admission to psychiatry department according with portuguese mental health law

Discharged with: $\checkmark$ Litium $800 \mathrm{mg}$ daily $\checkmark$ Quetiapine $300 \mathrm{mg}$ daily $\checkmark$ Aripiprazole $15 \mathrm{mg}$ daily $\checkmark$ Lorazepam $5 \mathrm{mg}$ daily

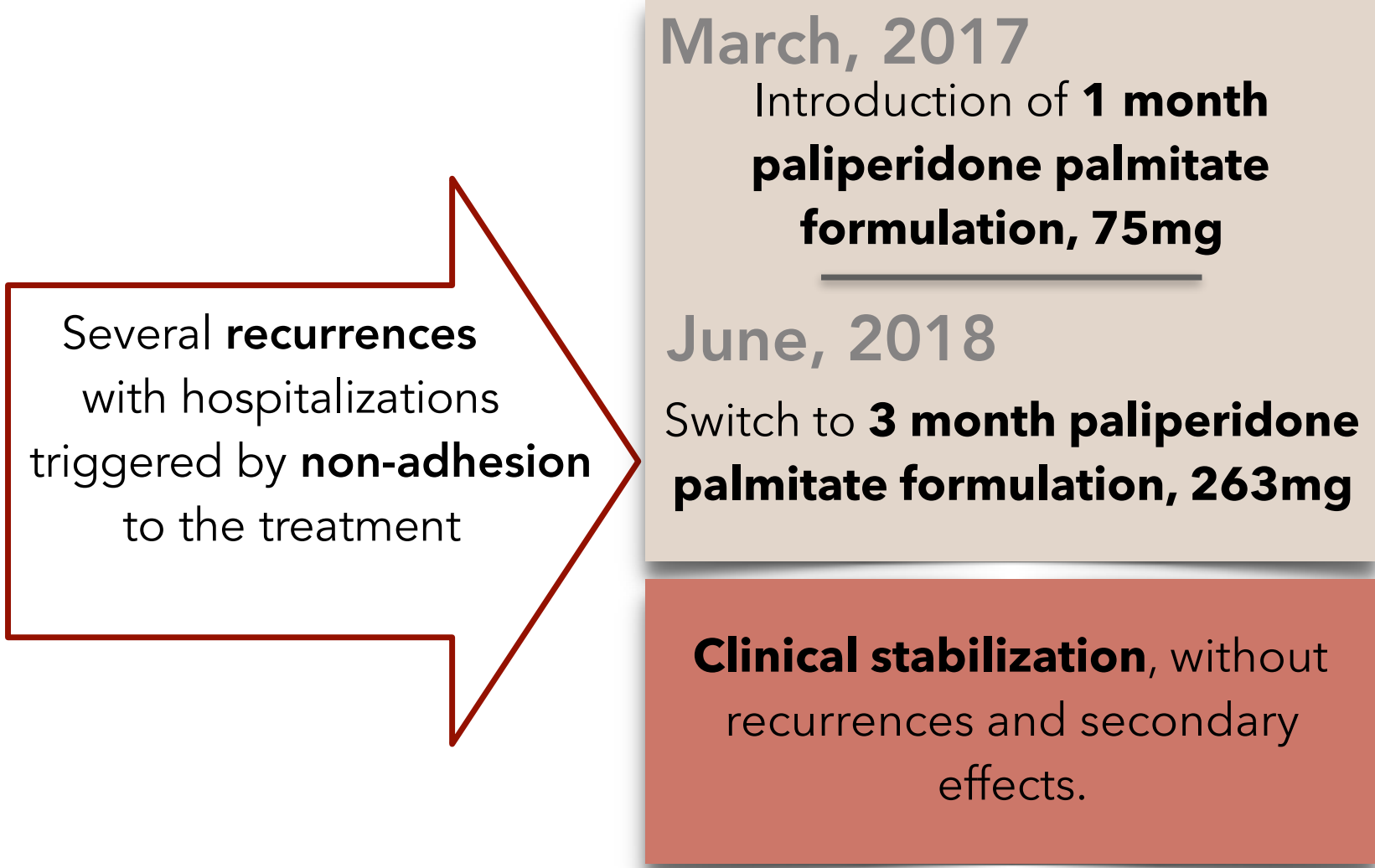

CONCLUSIONS

A major determinant of bad outcomes in BAD is the non-adherence to medication. In the past the only existing pharmacological option for bipolar patients with poor adherence to treatment was the long-acting injectable first-generation antipsychotics. Nowadays, other options are available to treat this disorder. However, until now, data about the use of paliperidone palmitate in BAD is very limited. In the presented case, as one-month formulation as three-month antipsychotic formulations were clinically effective, preventing relapses without side effects. In consequence, paliperidone palmitate may be a therapeutic option in cases similar to that presented. Therefore, more studies are necessary to prove the effectiveness of this antipsychotic in BAD. 